\title{
Scaling morphosemantic transparency/opacity: A corpus-linguistic and acquisitionist study of German diminutives
}

\author{
Sonja Schwaiger ${ }^{a *}$, Jutta Ransmayr ${ }^{a}, K^{2}$ atharina Korecky-Kröll ${ }^{a, b}$, \\ Sabine Sommer-Lolei ${ }^{\mathrm{a}, \mathrm{b}}$ and Wolfgang U. Dressler ${ }^{\mathrm{a}, \mathrm{b}}$ \\ ${ }^{a}$ Austrian Academy of Sciences, Vienna, ${ }^{b}$ University of Vienna \\ *sonja.schwaiger@oeaw.ac.at
}

\begin{abstract}
The judicious use of electronic corpora allows new possibilities in the study of word formation. In contrast to the usual way of contrasting morphosemantic transparency (or compositionality) and morphosemantic opacity (or non-compositionality) in a dichotomous way, we present a ten-step scale from maximum transparency to total opacity, exemplified with the common German diminutive suffixation in -chen and Austro-Bavarian -erl.

Our corpus-linguistic investigation allows new insights into problems of distribution of type and token frequency according to degrees of morphosemantic transparency/opacity and of the two rivalling diminutive formations.

An analysis of diminutive acquisition is added as external evidence for or against previous claims. Acquisition data come from three longitudinal corpora and from 24 children of a transversal quasi-longitudinal study. Here the order of acquisition of diminutives according to the ten-step scale of morphosemantic transparency/opacity and to adult type and token frequency will be presented and the relation between morphosemantic and morphopragmatic meaning will be discussed.
\end{abstract}

Keywords: diminutives; morphosemantic transparency; word formation; corpus linguistics.

\section{Introduction}

Analysis of electronic corpora allows new possibilities in the study of word formation. Progress can be made by having access to much more data both in types and tokens. This helps not just in the study of forms and their distribution but also for more fine-grained semantic investigations. Morphosemantic transparency and opacity holds between the meaning of a complex word to 
its morphological elements. Optimal morphosemantic transparency holds if there is an equivalence between the lexical meaning of the whole and the constructed result of rule-governed combination of the meaning of the morphological parts, i.e. what has been called in German Wortbildungsbedeutung 'word-formation meaning' (Barz 1983; Motsch 1999: 26) and what is called in Corbin's (1987) tradition sens construit (Fradin 2009: 97-98). There is a common trend in the literature (Dressler 1985, 2005, 2006; Crocco Galéas and Dressler 1992 with further references) to claim a preference for morphosemantic transparency over opacity, especially for inflectional morphology, whereas it is counterbalanced in word formation by lexicalization. These claims are still stronger for early stages of first language acquisition.

In this perspective, we aimed at investigating the amount of morphosemantic transparency/opacity in both adult and child language, but not in a simplistic semantic dichotomy of transparency vs. opacity. With our corpus analysis we show how such simplistic semantic dichotomies can be overcome, in our case the usual linguistic and psycholinguistic way of contrasting morphosemantic transparency (or compositionality) and morphosemantic opacity (or non-compositionality) as a dichotomy. The area investigated are the two fully productive Austrian German diminutive suffixations, i.e. the suffixes Common German -chen and Bavarian and Austrian German -erl (with its allomorphs -tscherl, -tschkerl and haplological $-l$ after word-final $/ \varepsilon r /$ ). We analyzed the representation of these diminutive suffixations in the greatest electronic corpus of Austrian German as well as in first language acquisition in longitudinal and transversal electronic child corpora.

\section{Scaling morphosemantic transparency}

Since a scale of morphotactic transparency has been successfully established and applied (Dressler 1985, 2005; Talamo et al. 2016), also the continuum between optimal morphosemantic transparency, as in Pol. kot-ek 'small/nice cat' (from simplex kot) and total opacity should be modelled by a scale, because so far we usually find only a binary distinction between transparency and opacity, either in regard to the whole complex word or to the contribution of each of its parts (e.g. Libben 2010, 2014; Gagné and Spalding 2016). An example of the latter approach is the classification of the English compound eye+tooth as having an opaque first and a transparent second member. For diminutives attempts at a very restricted gradation can be found in Well- 
mann (1975: 124, 127-135; Klimaszewska 1983; Ott 2011). For restricted gradation in other areas of word formation note Bourque (2014), Talamo et al. (2016). In Ransmayr et al. (2016) we have proposed a ten-step scale of morphosemantic transparency/opacity of derivational morphology, exemplified with German diminutive suffixations in -chen. This gradation is restricted to semantic meanings of denominal diminutives, morphopragmatic meanings, which are restricted to morphosemantically very transparent diminutives (cf. Dressler and Merlini Barbaresi 1994) are excluded because hardly amenable to automatic tools of corpus-linguistic research (for the possibility of pragmatic scaling cf. Kilani-Schoch et al. 2011). We have claimed (Dressler and Merlini Barbaresi 1994, 2017; Merlini Barbaresi 2015) that the basic morphopragmatic meaning of diminutive formation is to characterize the speech situation and/or the speech-act as non-serious and fictional, whereas change of the morphosemantic meaning refers only to the word to which a diminutive suffix is attached. A corpus-linguistic analysis of such morphopragmatic meanings would require to control each token of a diminutive in its context. Therefore the only pragmatic aspect that we can investigate corpus-linguistically is the lexical pragmatic meanings attached via diminutive formation to a single lexical base, independent of context and speech act.

The presented scaling (see Table 1) applies to either the only or the main meaning of a word (in terms of corpus-linguistic frequency), minor meanings of polysemous words are neglected, and the scale applies to the relation of the suffix to the immediately preceding nominal lexical element, not to the meaning of the whole in case of a multimember compound. For example in the following scale Busch-wind-rös-chen 'bush-wind-rose-DIM = wood anemone' is classified as a case of degree 5 of morphosemantic transparency/ opacity because it is not a rose. Since there does not exist a word *Buschwind-rose, no classification of its meaning contribution would be possible.

\section{Data and methods}

The electronic data base for the corpus-linguistic analyses consists of nearly 19,000 different diminutives which have at least 5 tokens within the Austrian Media Corpus (AMC) of the Austrian Academy of Sciences (see also Ransmayr et al. 2017), which comprises all Austrian print media from 1990 onwards. 
Table 1. Scale of relative morphosemantic transparency/opacity.

\begin{tabular}{|c|c|}
\hline Degre & Properties, examples of German -chen/-erl diminutives \\
\hline 1 & $\begin{array}{l}\text { Optimal transparency: } X \text {-chen is a small, nice, unimportant } X \text { : Gläs-chen = } \\
\text { Glas-erl 'glass-DIM', cf. Lämp-chen = Lamp-erl 'lamp-DIM', Städt-chen } \\
=\text { Stadt-erl 'town-DIM'. }\end{array}$ \\
\hline 2 & $\begin{array}{l}\text { Slight lexical-pragmatic collocational restriction: Jäck-chen = Jack-erl } \\
\text { 'jacket-DIM', Schuh-chen = Schuch-erl 'shoe-DIM' preferentially or even } \\
\text { normally refer to their use by women and/or children, independent of lan- } \\
\text { guage user, context or speech act. }\end{array}$ \\
\hline
\end{tabular}

3 Semantic (thus stronger than lexical-pragmatic) collocational restriction, as in the main meanings of Herr-chen =Herr-l 'mi/aster-DIM', Frau-chen = Frau-erl 'woman/mistress-DIM' of their dog or cat, Brüst-chen = Brüst-erl 'breast-DIM' (in their main meanings only of meat), Viert-erl 'quarter-DIM' (nearly only meaning: 'quarter liter of wine').

4 Main meaning of base not or only partially preserved, lacking semantic features: Weib-chen 'woman-DIM = female animal', Männ-chen 'man-DIM' (main meaning: 'male animal').

5 Metaphoric motivation (a still rather strong type of semantic motivation, cf. de Knop 1987): Lüft-chen = Lüft-erl 'air-DIM = slight breeze', Buschwind-rös-chen 'bush-wind-rose-DIM = wood anemone' (looking similar to a rose), Stroh-rös-erl 'straw-rose-DIM' (rose-like straw decoration).

$6 \quad$ Weak semantic, often metonymic relation to base: Ständ-chen 'stand-DIM = serenade', Kränz-chen 'wreath-DIM = (coffee) circle', Nerv-erl 'nerve$\mathrm{DIM}=$ nervous person', Palm-kätz-chen $=$ Palm-katz-erl 'palm cat-DIM = catkin' (only faintly resembling a small cat).

$7 \quad$ Still weaker lexical motivation, but still somewhat SMALL: Gänse-fü $\beta$ chen 'goose-feet-DIM = quotation marks', Eich-hörn-chen 'oak-horn-DIM = squirrel', Reh-erl'deer-DIM = chanterelle'.

$8 \quad$ No synchronic base (acephalous), but weak diminutive meaning due to related words: Mäd-chen = Mäd-el = Mäd-erl = Mäd-i 'girl' (4 DIM), Flittchen $=$ Flitt- $(t)$ scherl 'slut'.

9 Neither synchronic base nor diminutive meaning, but possible metalinguistic semantic motivation via diachronically related words: Mär-chen 'fairy tale' and obsolete Märe 'story', Vintschg-erl 'small bread type originated in Vintsch-gau = Val Venosta in South Tyrol'.

10 Not even such motivation, only ends in -chen or -erl: Kaninchen 'rabbit', Veilchen 'violet', Schöberl 'type of soup noodles'. Since less than one in thousand nouns (except conversions from an infinitive in -en) ending in -chen or -erl are not diminutives of degrees 1 through 9, also this tiny remainder has the formal appearance of representing diminutives. 
These are 8,845 different -chen diminutives $(2,232,821$ tokens) and 3,386 different -erl diminutives $(469,867$ tokens). Thus in this journalistic genre the -erl diminutives identified as typically Austrian have just a bit more than half the types and tokens of the Common German diminutive. This is one instance of the tendency of Austrian print media to follow Common German norms.

The methodology of analysis consisted in first extracting automatically all noun-derived common nouns (i.e. not names) ending in -chen and -erl (including forms with case or plural endings), excluding automatically phonologically inadequate words (e.g. those which were too short, such as Kerl 'fellow' or where -chen was preceded immediately by a vowel or diphthong, e.g. Nachen 'skiff', Streichen '(the) sweeping'). In order to exclude erroneous examples, only those lexemes were analysed which had at least 5 tokens in the AMC. The limitation to diminutives which occur at least with 5 tokens also guarantees that they are lexicalized and not occasionalisms. Then, manually, still remaining erroneous examples were excluded and for polysemous diminutives the most frequent meaning was identified, thus excluding minor meanings from semantic analysis. The assignment of the diminutive lexemes to the 10 degree categories of Table 1 was done jointly by the authors. Whenever one of them disagreed, two more colleagues were consulted.

\section{Distribution of -chen and -erl diminutives in the Austrian Media Corpus}

The distribution of the two diminutive suffixations according to the ten degrees of morphosemantic transparency/opacity of Table 1 and according to their position after a simplex or a compound is listed in Tables 2 and 3.

First of all, in the position of the suffix after simplicia, the number of -chen and -erl lemmata is nearly identical. The huge difference between the two formations is due to both token frequencies and to the position after compounds. Thus the difference between the two lies clearly in profitability rather than in productivity (cf. Bauer 2001).

Second, the relations (ratio) between -erl and -chen diminutives differ in each row of the transparency scale (see Table 4). 
Table 2. Quantitative distribution of diminutives in -chen on the transparency scale.

\begin{tabular}{lrrrrrr}
\hline $\begin{array}{l}\text { CHEN- } \\
\text { Scale }\end{array}$ & $\begin{array}{c}\text { Types / } \\
\text { Lemmas }\end{array}$ & $\begin{array}{c}\text { Simplex- } \\
\text { DIM }\end{array}$ & $\begin{array}{c}\text { Simplex- } \\
\text { Tokens }\end{array}$ & Compound- Compound- & DIM & Tokens \\
\hline 1 & 4,609 & 695 & 496,171 & 3,914 & 193,689 & Tokens \\
2 & 392 & 50 & 32,437 & 342 & 11,144 & $43,58,860$ \\
3 & 680 & 20 & 86,198 & 660 & 38,374 & 124,572 \\
4 & 643 & 9 & 53,106 & 634 & 28,218 & 81,324 \\
5 & 232 & 6 & 13,331 & 226 & 13,684 & 27,015 \\
6 & 499 & 10 & 26,551 & 489 & 51,141 & 77,692 \\
7 & 407 & 11 & 24,531 & 396 & 31,525 & 56,056 \\
8 & 722 & 16 & 840,833 & 706 & 69,462 & 910,295 \\
9 & 564 & 4 & 122,672 & 560 & 42,331 & 165,003 \\
10 & 97 & 10 & 43,070 & 87 & 14,353 & 57,423 \\
\hline Total & 8,845 & 831 & $1,738,900$ & 8,014 & 493,921 & $2,232,821$ \\
\hline
\end{tabular}

Table 3. Quantitative distribution of diminutives in -erl on the transparency scale.

\begin{tabular}{lrrrrrr}
\hline $\begin{array}{l}\text { ERL- } \\
\text { Scale }\end{array}$ & $\begin{array}{r}\text { Types } / \\
\text { Lemmas }\end{array}$ & $\begin{array}{c}\text { Simplex- } \\
\text { DIM }\end{array}$ & $\begin{array}{c}\text { Simplex- } \\
\text { Tokens }\end{array}$ & $\begin{array}{c}\text { Compound- Compound- } \\
\text { DIM }\end{array}$ & Tokens & Tokens \\
\hline 1 & 1,939 & 643 & 137,948 & 1,296 & 70,286 & 208,234 \\
2 & 114 & 33 & 11,529 & 81 & 3,602 & 15,131 \\
3 & 363 & 51 & 68,544 & 312 & 12,707 & 81,251 \\
4 & 432 & 7 & 34,136 & 425 & 26,512 & 60,648 \\
5 & 65 & 5 & 3,024 & 60 & 2,916 & 5,940 \\
6 & 126 & 16 & 18,020 & 110 & 6,290 & 24,310 \\
7 & 133 & 8 & 31,780 & 125 & 5,739 & 37,519 \\
8 & 37 & 26 & 1,477 & 11 & 117 & 1,594 \\
9 & 38 & 16 & 8,104 & 22 & 769 & 8,873 \\
10 & 139 & 24 & 24,793 & 115 & 1,574 & 26,367 \\
\hline Total & 3,386 & 829 & 339,355 & 2,557 & 130,512 & 469,867 \\
\hline
\end{tabular}


Table 4. Ratio of all -erl vs.-chen diminutive lemmas.

\begin{tabular}{lccccc}
\hline \multirow{2}{*}{ Scale } & All DIM: & \multicolumn{2}{c}{ after simplicia $\%$} & \multicolumn{2}{c}{ after compounds \% } \\
\cline { 3 - 6 } & & -chen & - erl & -chen & -erl \\
\hline 1 & 6,548 & 10.61 & 9.81 & 59.77 & 19.79 \\
2 & 506 & 9.88 & 6.52 & 67.59 & 16.01 \\
3 & 1,043 & 1.92 & 4.89 & 63.28 & 29.91 \\
4 & 1,075 & 0.84 & 0.65 & 58.98 & 39.53 \\
5 & 297 & 2.02 & 1.68 & 76.09 & 20.20 \\
6 & 625 & 1.6 & 2.56 & 78.24 & 17.60 \\
7 & 540 & 2.04 & 1.48 & 73.33 & 23.15 \\
8 & 759 & 2.11 & 3.43 & 93.02 & 1.45 \\
9 & 602 & 0.66 & 2.66 & 93.02 & 3.65 \\
10 & 236 & 4.24 & 10.17 & 36.86 & 48.73 \\
\hline
\end{tabular}

Since the numbers of simplex lemmas are nearly identical, one can take the simplex ratios at their face value: at the two most transparent degrees of the scale there are more -chen diminutives. The more opaque the degrees are, the higher is the preponderance of -erl diminutives (with the exception of degree 6). Since productivity plus profitability and morphosemantic transparency favor each other, this distribution fits our expectations. The highest difference, i.e. among only apparent diminutives (degree 10), seems to be due to the historic fact that dialectal -erl diminutives have entered Austrian Standard German often without their historic simplex bases.

Looking at compound diminutives which contain three times more -chen than -erl diminutives, then the percentage of -erl diminutives rather decreases with rising opacity (with the notable exception of only apparent diminutives, i.e. degree 10). But if one considers that there are three times more compound -chen diminutives than -erl diminutives, then the chances of different percentages vanish in degrees $1,5,7$, refined -erl diminutive percentages dominate only in degrees 3 and 4 , whereas refined -chen diminutive percentages dominate in degrees $2,6,8,9$. The only reasonable explanation is that at degrees 8 and 9 the remaining small amount of transparency is of a metalinguistic nature and that there is more possibility of metalinguistic as- 
sociations for the common Standard German -chen suffixations and especially in compounding in the print media than for dialect-based -erl suffixations. But all this needs intensive qualitative dialect and diachronic analyses. Furthermore, it must be studied whether compounds are used more in the print media than in other genres.

-chen and -erl diminutives derived from the same base often have different degrees of transparency/opacity as listed in the following examples:

- Stand-erl (degree 1) 'small selling stand' vs. Ständ-chen (degree. 6) 'serenade';

- Platz-erl (degree 1) 'small space' vs. Plätz-chen (degree 7) 'fancy cake' (main meaning);

- Kranz-erl (degree 1) 'small wreath' vs. Kränz-chen (degree 6) '(coffee) circle';

- Gans-erl (degree 3) 'goose meat' (main meaning) vs. Gäns-chen (degree 1) 'small goose = chick' (main meaning);

- Schüss-erl (degree 5) 'tiny car' vs. Schüssel-chen (degree 1), bowlDIM'.

For the establishment and delimitation of derivational series, of family size in word formation, left- vs. right-branching of trimorphemic diminutives, gender bias in diminutive compounding see Ransmayr et al. (2016), rivalry between diminutive suffixation and the status of lexical blocking see Dressler et al. (2016).

Our main research question, whether the claimed preference for morphosemantic transparency over opacity holds also for word formation despite of lexicalisation of all established complex words, can be answered in a positive way for diminutives. Optimal transparency on our scale (degree 1) is true for more than half (52\%) of all -chen diminutives (which occur with at least 5 tokens in the AMC), and for $57 \%$ of all -erl diminutives. And if one adds the fairly transparent degrees 2 and 3, one arrives at $64 \%$ of all -chen diminutives and $71 \%$ of all -erl diminutives respectively. Since diminutive formation is a representative of non-prototypical word formation and is therefore more similar to inflection than prototypical word formation (Dressler 1989), it would be possible that the percentage of morphosemantically transparent derivations and compounds is much smaller in prototypical than in non-prototypical word formation. 


\section{Distribution of diminutive suffixes -chen and -erl in first language acquisition}

We investigated whether the preference for morphosemantically transparent morphology is still stronger in early child language, as generally claimed for word formation in the literature (Slobin 1985: Clark 1993: Dressler 1985: 2005, 2006).

Our Viennese acquisition data come from three longitudinal corpora of spontaneous interaction between children and parents (children's age ranges: $1 ; 3-6 ; 0,1 ; 6-3 ; 0,1 ; 7-3 ; 0)$ and from 24 children of a transversal quasi-longitudinal study (with 4 collection data points at the mean ages: $3 ; 1,3 ; 4,4 ; 4$ and 4;8, cf. Korecky-Kröll 2017; Savickiene and Dressler 2007). Table 5 shows the distribution of transparent and opaque diminutive formations.

Table 5. Distribution of transparent (degree 1) and opaque child speech diminutives.

\begin{tabular}{lcccccc}
\hline & \multicolumn{3}{c}{ Transparent } & \multicolumn{2}{c}{ Opaque } & \multicolumn{2}{c}{ Inflection } \\
\cline { 2 - 7 } & Lemmas & Degree 1 & Degrees 2-7 Degrees & 8-10 & Types & Tokens \\
\hline -erl & 86 & 67 & 15 & 4 & 106 & 277 \\
-chen & 40 & 28 & 8 & 4 & 45 & 108 \\
\hline
\end{tabular}

Some examples (all with more than 1 token in the corpora) are: Astronaut-erl 'astronaut-DIM' (degree 1), Flasch-erl 'bottle-DIM (for babies)' (2), Schwamm-erl 'sponge-DIM = mushroom' (3), Mand-erl = Männch-en 'manDIM = manikin (as toy)' (4), Zucker-l 'sugar-DIM = bonbon' (5), Leib-erl= Leib-chen 'body-DIM = bodice' (6), Fisch-stäb-chen 'fish-rod-DIM = fish stick' (7), Mädchen 'girl' (8).

In comparing fully transparent diminutives with opaque ones we must take out the 8 lemmas with opacity degrees $8,9,10$, because these are for children like simplicia (since they do not have yet the metalinguistic skills for identifying diminutivity in these lemmas). This results in the lemma ratios of 64 fully transparent vs. 19 less transparent -erl diminutives and of 31 fully transparent vs. 5 less transparent -chen diminutives. This confirms the claim (see $\S 1$ ) that small children have a stronger preference for morphosemantic transparency than adults, at least in the case of diminutives. 
Looking only on the three longitudinal corpora, which represent acquisition phases up to 3 years of age and thus earlier phases than the transversal data, we find for -chen diminutives that 16 lemmas of transparency degree 1 emerge and 4 of degrees 7, 8 and 10, but none of intermediate degrees of transparency/opacity. This means that children acquire fully transparent and thus easily decomposable diminutives and a few fully lexicalized opaque ones which they cannot yet decompose, which provides further evidence for the advantage of differentiating degrees of morphosemantic transparency/opacity.

The distribution is different for the -erl diminutives, which they prefer. 24 of 41 diminutives are fully transparent (degree 1), 7 are of the very opaque degrees $7-10$. The remaining 10 diminutives represent all intermediate degrees of opacity (2-6). Of these opaque ones they produce relatively early those which are of prime importance for them: Flasch-erl 'bottle-DIM (for babies)' (2), Zuck-erl 'sugar-DIM = bonbon' (5) and Leib-erl 'body-DIM = bodice' (6), where obviously the pragmatics of usage is more relevant than transparency.

\section{Conclusion}

These acquisition results, in a spectacular way, confirm the claim that children first acquire diminutives (as representatives of word formation) with transparent meanings and prefer morphosemantic transparency to opacity still to a greater degree than adults. Moreover the acquisition results are compatible with our earlier findings (Savickiene and Dressler 2007; Dressler and Korecky-Kröll 2015) that children acquire basic pragmatic meanings of diminutives before they acquire semantic meanings of smallness, because speech-act pragmatic meanings are compatible only with morphosemantic transparency of degrees 1 and 2. And this in turn supports our claim (Dressler and Merlini Barbaresi 1994, 2001, 2017) of a priority of pragmatic over semantic meanings of diminutives.

The corpus-linguistic analysis of the adult written corpus of AMC also confirms the adults' preference for transparent meanings and that this is not a dichotomous but a gradual preference, which holds for both diminutive suffixations investigated. The scale of morphosemantic transparency/opacity has allowed to show different distributions of each suffixations. A manuscript submitted by Schwaiger et al. (2017) shows also strikingly diverse distribu- 
tions of each suffixations in different genres and one nearly finished by Ransmayr et al. (to be submitted) different distributions in different lexical areas. Clearly our scaling of morphosemantic transparency/opacity must be extended to other areas of word formation, as has been attempted for English compounds in Mattiello and Dressler (2017 submitted).

\section{References}

Barz, I. 1983. "Wortbedeutung und Wortbildungsbedeutung”. Zeitschrift für Germanistik 4. 65-69.

Bauer, L. 2001. Morphological productivity. Cambridge: Cambridge University Press.

Bourque, S.Y. 2014. Toward a typology of semantic transparency: The case of French compounds. (PhD dissertation, Department of French Studies, University of Toronto.)

Clark, E.V. 1993. The lexicon in acquisition. Cambridge: Cambridge University Press.

Corbin, D. 1987. Morphologie dérivationnelle et structuration du lexique. Tübingen: Niemeyer.

Crocco Galèas, G. and W.U. Dressler. 1992. "Trasparenza morfotattica e morfosemantica dei composti nominali più produttivi dell'italiano di oggi." In: Moretti, B., D. Petrini and S. Bianconi (eds.), Atti del 25. Congresso Società di Linguistica Italiana. Roma: Bulzoni. 9-24.

de Knop, S. 1987. Metaphorische Komposita in Zeitungsüberschriften. Tübingen: Niemeyer.

Dressler, W.U. 1985. "On the predictiveness of Natural Morphology”. Journal of Linguistics 21. 321-337.

Dressler, W.U. 1989. "Prototypcial differences between inflection and derivation". Zeitschrift für Phonetik, Sprachwissenschaft und Kommunikationsforschung 42. $3-10$.

Dressler, W.U. and L. Merlini Barbaresi. 1994. Morphopragmatics. Berlin: Mouton de Gruyter.

Dressler, W.U. and L. Merlini Barbaresi. 2001. "Morphopragmatics of diminutives and augmentatives: On the priority of pragmatics over semantics". In: Kenesei, I. and Robert Harnish (eds.), Perspectives on semantics, pragmatics, and discourse. A Festschrift for Ferenc Kiefer. Amsterdam: Benjamins. 43-58.

Dressler, W.U. 2005. "Word-formation in Natural Morphology". In Štichauer, P. and R. Lieber (eds.), Handbook of word-formation. New York: Springer. 267-284.

Dressler, W.U. (ed.). 2006. Natural Morphology. (Folia Linguistica 40, special issue.) $1-2$.

Dressler, W.U. and K. Korecky-Kröll. 2015. "Evaluative morphology and language acquisition". In: Grandi, N. and L. Körtvélyessy (eds.), Edinburgh handbook of evaluative morphology. Edinburgh: Edinburgh University Press. 134-141. 
Dressler, W.U. and L. Merlini Barbaresi. 2017. "Pragmatics and morphology: Morphopragmatics." In: Huang, Y. (ed.), The Oxford handbook of pragmatics. Oxford University Press. 493-510.

Dressler, W.U., L. Merlini Barbaresi, S. Schwaiger, J. Ransmayr, S. Sommer-Lolei and K. Korecky-Kröll. 2017. "Rivalry and lack of blocking among Italian and German diminutives in adult and child language". In: Rainer, F., F. Gardani, H. Luschützky and W.U. Dressler (eds.), Competition in morphology. Berlin: Springer. In print.

Fradin, B. 2009. "Morphologie constructionnelle et sémantique". Mémoires de la Société de Linguistique de Paris 17: La morphologie lexicale: un domaine autonome de la grammaire? 89-118.

Gagné, C.L. and T.L. Spalding. 2016. "Written production of English compounds: Effects of morphology and semantic transparency". Morphology 26(2). 157-200.

Kilani-Schoch, M., F. Sánchez Miret and W.U. Dressler. 2011. "Towards naturalness scales of pragmatic complexity". Poznań Studies in Contemporary Linguistics 47. 237-263.

Korecky-Kröll, K. 2017. "Kodierung und Analyse mit CHILDES: Erfahrungen mit kindersprachlichen Spontansprachkorpora und erste Arbeiten zu einem rein erwachsenensprachlichen Spontansprachkorpus". In: Resch, C. and W.U. Dressler (eds.), Digitale Methoden der Korpusforschung in Österreich. Vienna: Verlag der Österreichischen Akademie der Wissenschaften. 87-113.

Libben, G. 2010. "Compounds, semantic transparency and morphological transcendence". In: Olsen, S. (ed.), New impulses in word formation. Hamburg: Buske. 212-232.

Libben, G. 2014. "The nature of compounds: A psychocentric perspective." Cognitive Neuropsychology 31. 8-25.

Mattiello, E. and W.U. Dressler. 2017. "The morphosemantic transparency/opacity of novel English analogical compounds and compound families". (Submitted to Journal of English Linguistics.)

Merlini Barbaresi, L. 2015. "Evaluative morphology and pragmatics". In: Grandi, N. and L. Körtvélyessy (eds.), Edinburgh handbook of evaluative morphology. Edinburgh: Edinburgh University Press. 32-42.

Motsch, W. 1999. Deutsche Wortbildung in Grundzügen. Berlin: de Gruyter.

Ransmayr, J., K. Mörth and M. Durco. 2017. "AMC (Austrian Media Corpus) 'Korpusbasierte Forschungen zum Österreichischen Deutsch'”. In: Resch, C. and W.U. Dressler (eds.), Digitale Methoden der Korpusforschung in Österreich. Vienna: Verlag der Österreichischen Akademie der Wissenschaften. 27-38.

Ransmayr, J., W.U. Dressler and S. Schwaiger 2017. "Semantische Untersuchungen zu österreichischen Diminutiven und Diminutivkomposita: Wortfelder und Graduierung der morphosemantischen Opazität". (To be submitted.)

Savickiene, I. and W.U. Dressler (eds.). 2007. The acquisition of diminutives: $A$ cross-linguistic perspective. Amsterdam: Benjamins.

Schwaiger, S., A. Barbaresi, K. Korecky-Kröll, J. Ransmayr and W.U. Dressler. 2017. "Diminutivvariation in österreichischen elektronischen Korpora". (Submitted as a conference paper for the conference Deutsch in Österreich und an- 
dere plurizentrische Kontexte: Variation - Kontakt - Perzeption. Vienna: 07 Jul 2017-09 Jul 2017.)

Slobin, D.I. 1985. "Crosslinguistic evidence for the language-making capacity". In: Slobin, D.I. (ed.), The crosslinguistic study of language acquisition. (Vol. 2.) Hillsdale: Lawrence Erlbaum. 1157-1249.

Talamo, L., C. Celata and P.M. Bertinetto. 2016. "/derIvaTario/: A lexicon of annotated Italian derivatives". Word Structure 9. 72-102.

\section{Address correspondence to:}

Sonja Schwaiger

Austrian Centre for Digital Humanities

Section "Variation and Change of German in Austria"

Austrian Academy of Sciences (ÖAW)

Postgasse 7-9

A-1010 Vienna

Austria

sonja.schwaiger@oeaw.ac.at 